\title{
Histological and Immunohistochemical Evaluation of Local Exogenous Application of the Green Tea on Bone Healing (Experimental Study On Rats)
}

\author{
Enas Fadhil \\ B.D.S.,MSc.,Ph.D., in oral histology \\ College of Dentistry University of Baghdad,Iraq
}

\begin{abstract} ization of bone morphogenic protein 2. that is detected to fill the most of bone defect in comparism with control group.

\section{INTRODUCTION}

Bone is a composition tissue that consists of organic components, type I collagen, non collagenous proteins and in organic components, mainly hydroxyapatite crystals (Nanci, et al., 2008), The two main categories of bone cells are osteoblasts that form the bone and osteoclasts that resorb (dissolve) the bone. The combined and cooperative activities of osteoblasts and osteoclasts result in a bone architecture that provides mechanical support and protection for the body. In addition, bone serves as a vital reservoir of minerals, principally calcium and phosphorus, necessary for maintaining normal cellular, neurologic, and vascular activities of the body (Nijweide et al., 2010).
\end{abstract}

Background: The study was designed to identify the role of local exogenous green tea in bone healing .

Material and method: Thirty male albino rats, were subjected for bone defects in medial sides of both tibia bone (right tibia was considered as experimental site with $1 \mu$ l of extract green tea, while the left be the control one, (treated with $1 \mu l$ of normal saline). The rats were scarified at $3,7,10$ days post surgery. Bone healing was histologically examined with immunohistochemical for local-

Results: show bone healing treated with extracted green tea illustrated to be faster in apposition of ostoid and bone trabeculae

Conclusion: Our results indicate that low application of exogenous green tea could be an effective therapeutic for bone injures, these data are promising for a possible future clinical usage especially for enhancement of bone healing.

Both osteoblastic and osteoclastic cells regulate bone metabolism, and both cell types are involved in the development of osteoporosis (Nijweide et al., 2010).. Osteoblasts, the bone-forming cells, locate near the surface of the bone and produce cytokines that affect osteoclasts. viable osteoblasts acting in concert with multiple growth factors(Matsuo et al., 2008), which are essential for the repair and regeneration of bone. Spescific growth factors important to bone formation include fibroblast growth factor 2, platelet-derived growth factor, vascular endothelial growth factor, Insulin like growth factor, bone morphogenic protein 2,4and 7, and transforming growth factor-beta (Singer et al.,2011).

Tea, the dried leaves of the Camellia sinensisspecies of the Theaceae family, is a popular beverage with an annual production of three billion kilograms worldwide (Yang et al., 2000). In the past decade, epidemiological evidence has shown an association between tea consumption and the prevention of age-related bone loss in the elderly population. The objective of this research is to study the benefits of local application of green tea as exogenous biomaterial on bone healing. As the use of green tea is a first trial to study in healing process.

Green tea polyphenols (GTP) have positive effects on bone mass and microarchitecture in both models of bone loss (She et al., 2008; Shen et al., 2009). Green tea prevented the aging-induced as well as aging plus estrogen deficiency-induced reduction in femoral bone mass (i.e., bone mineral content (BMC) and density (BMD), respectively (Chwan-Li et al., 2011). Serum osteocalcin (a bone formation biomarker) was elevated by the GTP treatment, while serum tartrate-resistant acid phosphatase (TRAP, a bone resorption biomarker) was suppressed by the GTP treatment (Wang et al., 2008) .

Green tea poly phenols supplementation was shown to suppress oxidative stress (as shown by decreased urinary 8-hydroxy-2'-deoxyguanosine levels) and inflammation (as shown by suppressed mRNA expression of tumor necrosis factor- $\alpha$ and cyclooxygenase- 2 in spleen). Authors concluded that GTP mitigates bone loss in a chronic-inflammationinduced bone loss model by reducing oxidative stressinduced damage and inflammation ( Shen et al., 2009; Shen et al.,2010).

One particular green tea compound called Epigallo-catechin (EGC), led to an increase in this enzyme's activity by $79 \%$. It also increased levels of bone mineralization in these cells: a vital part of strengthening bones (Mount et al.,2006).

Epi- gallo-catechin also suppressed the activity of cells called osteoclast cells that weaken and break down old bone, part of the natural process of bone 
remodelling. (Choi et al.,2003).

\section{MATERIALS AND METHODS}

The study was designed to illustrate the effectiveness of application of the local exogenous extracted green tea gel by studying bone specimens histologically and identification of bone morphogenic protein 2 in bone tissue.

All experimental procedures were carried out in accordance with ethical principles of animal experimentation.

\section{Experimental animals}

In this research, thirty male albino rats, weighing (320-500) gram, aged (6.5-8) months were used and maintained under control conditions of temperature, drinking and food consumption.

The animals were subjected for bone defects in medial sides of both tibial bone ( right tibia was considered as experimental site, while left be the control one), the animals were divided into two groups

1.Control group the bone defect treated with $1 \mu 1$ normal saline.

2.Experimental group includes 10 rats, the bone defect treated with $1 \mu \mathrm{l}$ extracted green tea gel . The rats were sacrified at 3, 7.10 days post surgery.

\section{Materials}

\section{Extracted green tea gel \\ Methods}

The animals were subjected for a surgical operation. The surgery was performed under a well sterilized condition and gentle technique. Every animal was weighted to calculate the dose of general anesthesia that was given to it. The general anesthesia was induced by Intra muscular injection of xylazine $2 \%(0.4 \mathrm{mg} / \mathrm{kg}$ B.W.), plus ketamine HCL 50mg (40 mg/kg- B.W.also an antibiotic cover with oxytetracycline $20 \%$ ( $0.7 \mathrm{ml} / \mathrm{kg}$ ) intramuscular injection was given. Then the animal was placed on the surgical table and the surgical towel was placed under the site of the operation. Both tibiae were shaved using cream from the inner side and the skin was cleaned with a mixture of ethanol and iodine then a piece of cotton damped with alcohol and left covering the shaved skin for one minute. Surgery was performed under sterile condition and gentle surgical technique. The cotton was removed. Incision was made on the lateral side to expose the medial side of the tibia, the skin and fascia flap was reflected. By intermittent drilling, and continuous cooling with irrigated saline, ahole of $1.8 \mathrm{~mm}$ was made with small round bur. Bone penetration was performed at a rotary speed of 1500 rpm. Following the hole preparation, the operation site was washed with saline solution to remove debris from the drilling site. Bone defect was made on both medial sides of right and left tibia bone, experimental and control sites.

After operation drying the area by air, then applied extracted green tea gell $\mu 1$.While normal saline $1 \mu \mathrm{ml}$ was used for control. Suturing of the muscles was done with absorbable catgut followed by skin suture. The operation site was sprayed with local antibiotic (tetracycline spray), also long acting systemic antibiotic oxy-tetracycline $20 \%(0.7 \mathrm{ml} / 1 \mathrm{~kg})$ was given to the animals after the surgery. Post operative care was performed by giving an antibiotic ( local and systemic). The animals were scarified at intervals 3,7,10 day, using over dose anesthesia . Five animals for each period, for each group. The tibia bone was dissected and fixed in $10 \%$ buffered formalin. Histological examination was done for all samples under light microscope.

\section{Assessment for immunohistochemistry results}

Positive reading was indicated when the cells display a brown cytoplasmic stain, while negative reading was indicated for absence of immunereactions depends on positive and negative control.

\section{Immunohistochemical scoring of BMP2}

Quantification method of Immunoreactivity was semiquantitatively estimated the immune-staining score that was calculated as the sum of a proportion score. The proportion score reflects the estimated fraction of positively stained infiltrating cells: score 0 : none. score $1:<10 \%$.score $2: 10-50 \%$. score $3: 51-80 \%$.score $4:>80 \%$. The intensity score represents the estimated staining intensity (score0, no staining, score1weak,score2 moderate, score3 strong), Hillmann et al.,1999.

\section{RESULTS}

\section{Histological findings}

Control group at 3 Days duration shows bone marrow infilterated by inflammatory cells with newly formed blood vessels; (Figure 1). Bone healing site for Control 7 Days duration shows fibrous tissue, with progenitor cell and fibroblast cell; (Figures 2). Trabeculated bone coalesce with cutting bone. Osteoblast, osteocyte and reticular cells aew detected at 10 day post operative period ( Figures 3,4).

Figure 3.1 Microphotograph view for control group (3 days) shows progenitor cell (arrow head), inflammatory cell (arrow).H\&EX20 


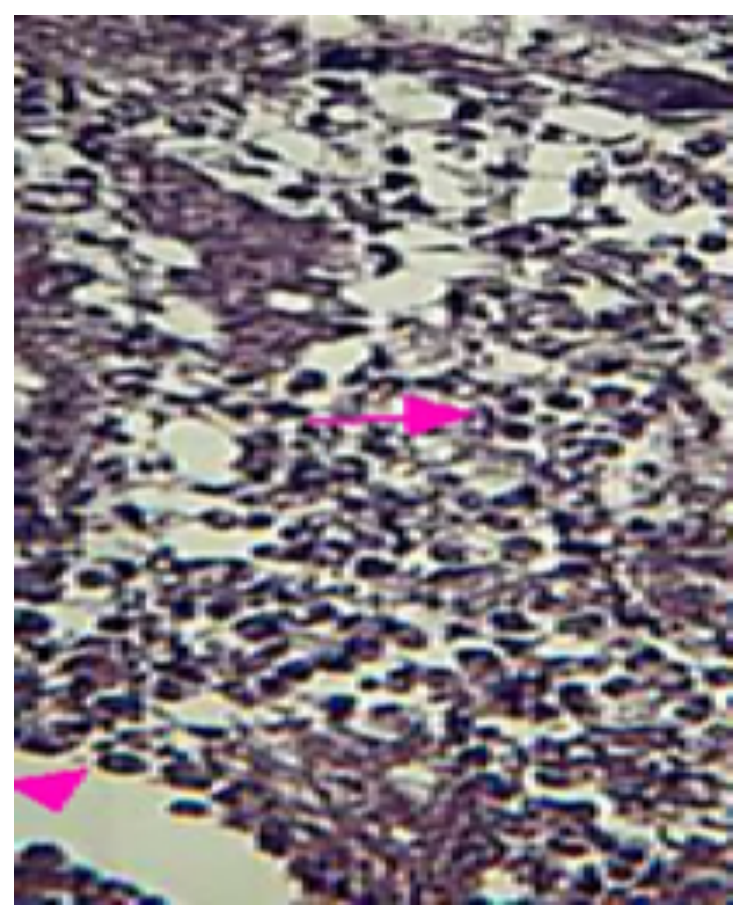

Figure2:View for bone healing site (control 7 days) shows

fibrous tissue (FT) with progenitor cell (arrow head), fibroblast (arrow).H\&EX20

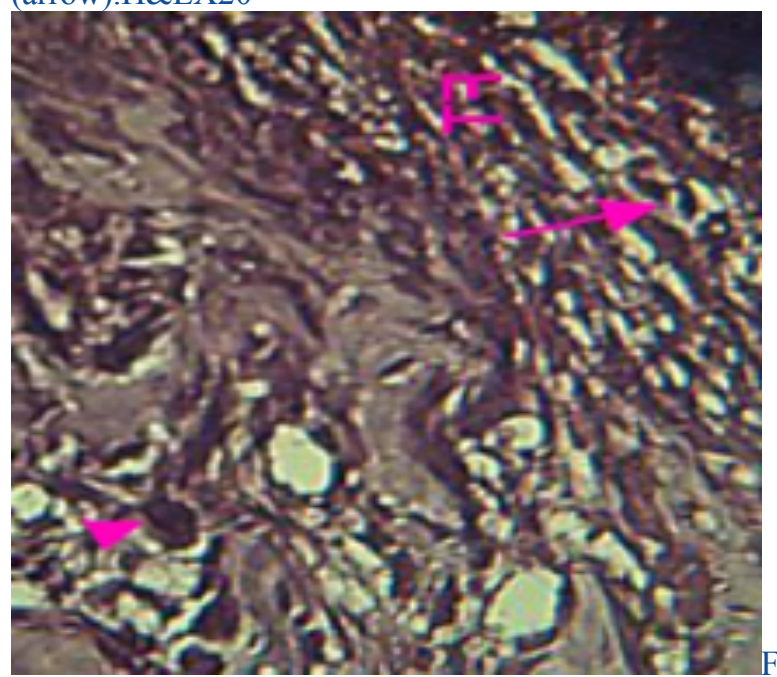

(CB) in control group 10 days. H\&EX20

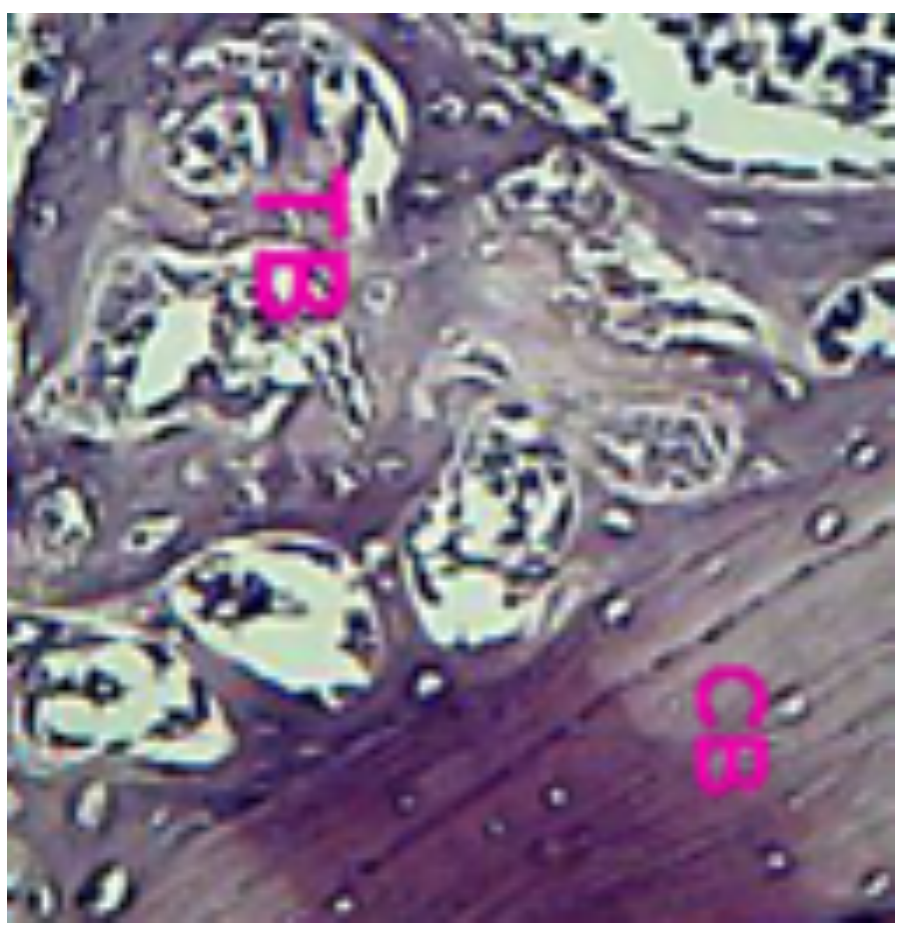

Figure 4 View for osteoid tissue (OT) filled the bone defect in green tea gel group at 3 days. H\&EX20

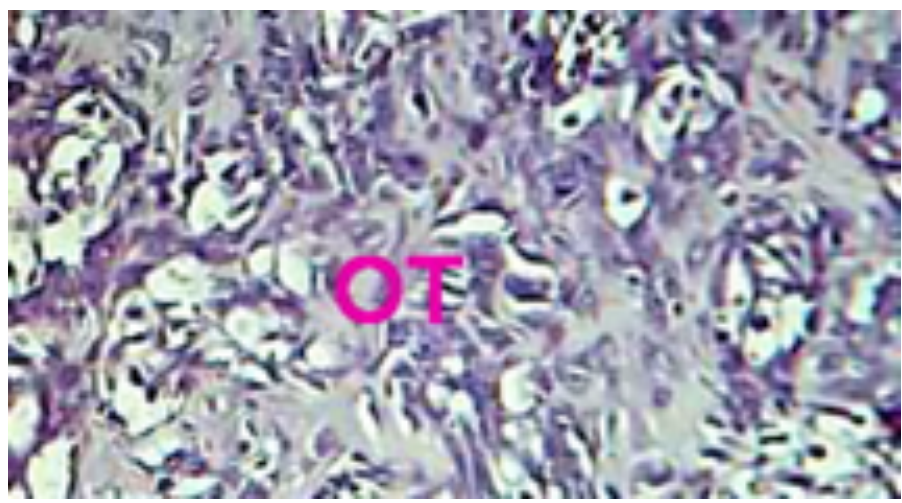

Figure 5: New blood vessels (arrow heads) in developing osteoid tissue. H\&EX40

ure3:View for trabeculated bone (TB) coalese with cutting bone

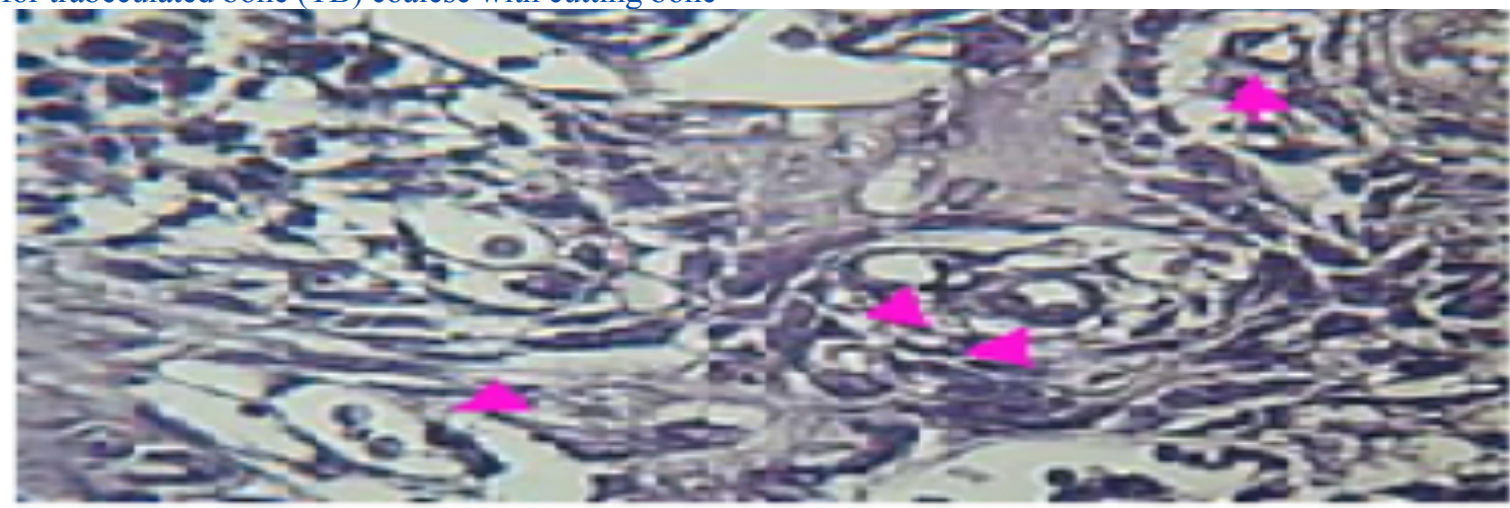

Figure 6:Trabeculated bone (TB), Coalesce with cutting bone (CB) in green tea gel group 7 days. H\&EX20 


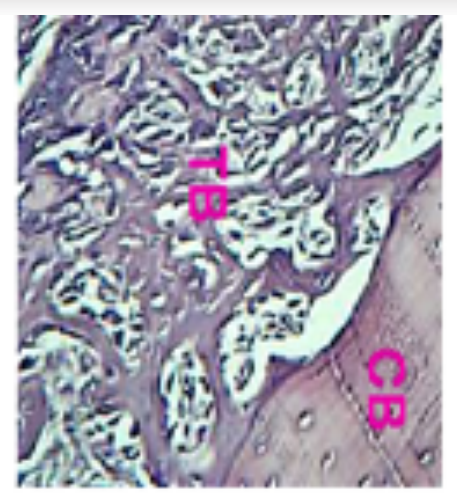

Figure7:View for highly cellular osteoid tissue.H\&EX40

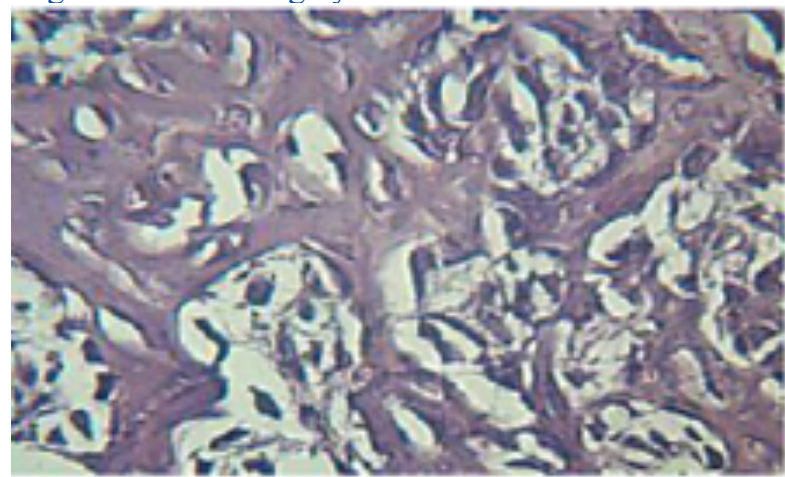

Figure 8: New bone (NB) with multiple haversian canal (HC), in nearly cutting bone (CB). H\&EX20

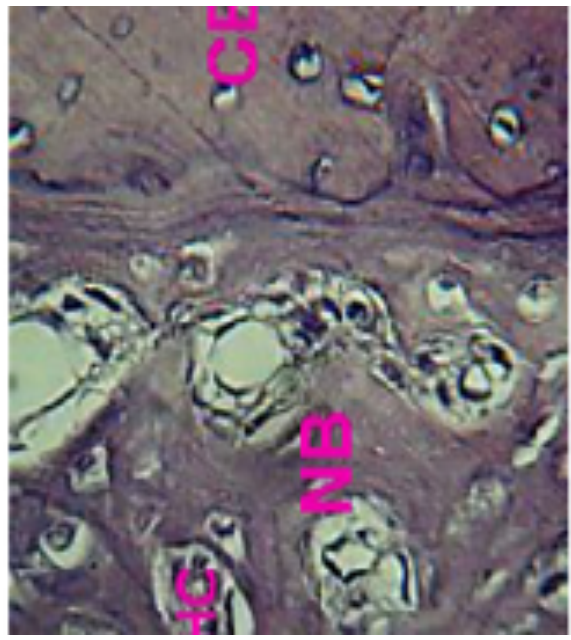

Experimental group: Bone treated with extracted green tea gel illustrated osteoid tissue filled the bone defect with newly formed blood vessels is detected at 3 day Figures $(4,5)$. Trabeculated bone, coalesce with cutting bone in extracted green tea gel group 7 days with highly vascular ostoid tissue; Figures $(6,7)$ and the period 10 days illustrated new bone with multiple haverssian canal in nearby cutting bone; Figure (8).

\subsection{Immunohistochemical evaluation for} expression of bone morphogenic protein 2 Figure(9) Immunohistochemical view for control group 3 days shows positive bone morophogenic protein 2 expession by progenitor(arrow heads), inflammatory cell (green arrow), endothelial cell (pink arrow). DAB stainX20.

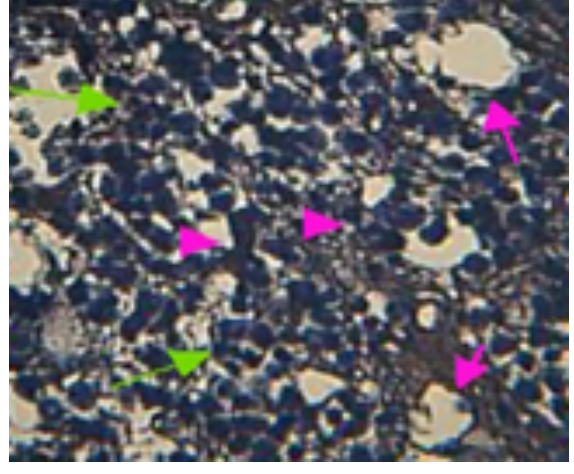

Figure (10) Osteprogenitor cell (arrow heads) and osteoblast (arrow) show positive BMP2 expression. DAB stainX40

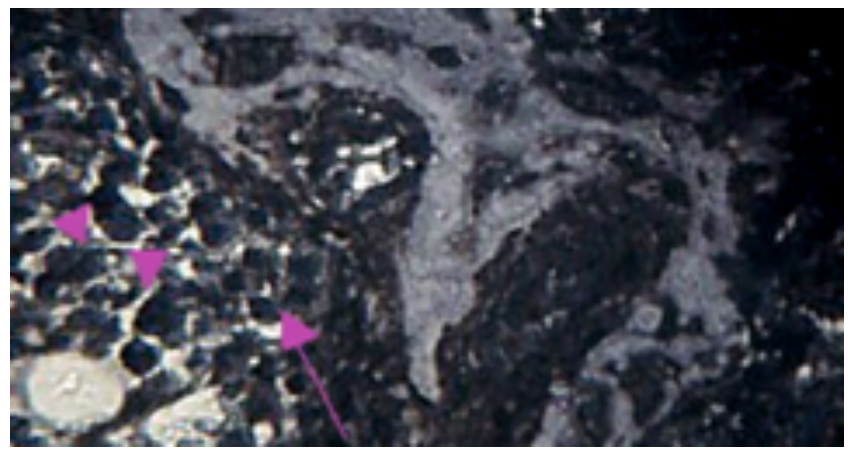

Figure (11) Osteoblast (arrows), reticular cell (arrows heads) show positive BMP2 expression in control group 10 days. DAB stainX40

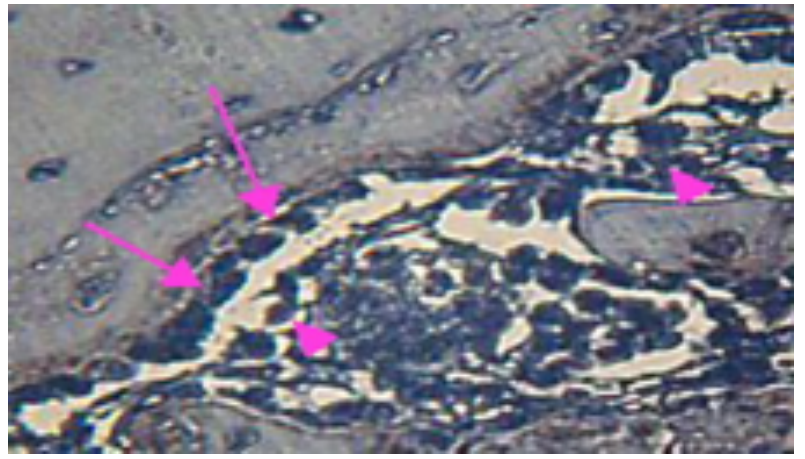

Figure(12) Immunohistchemical view for positive BMP2expressed by osteoprogenitor cell (arrows) in green tea gel group 3 days. DAB stainX20

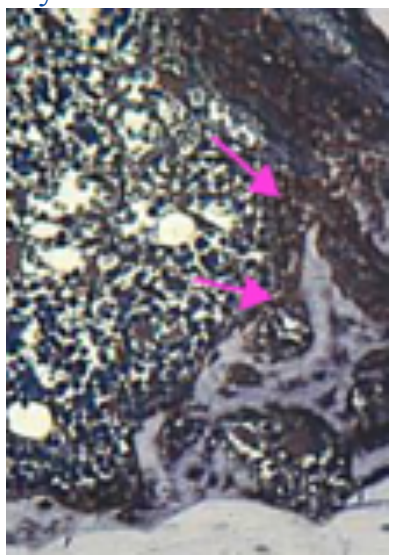

Figure (13) Osteoblast (arrows) and progenitor cell (arrow heads) expressed positive BMP2. DAB stainX40 


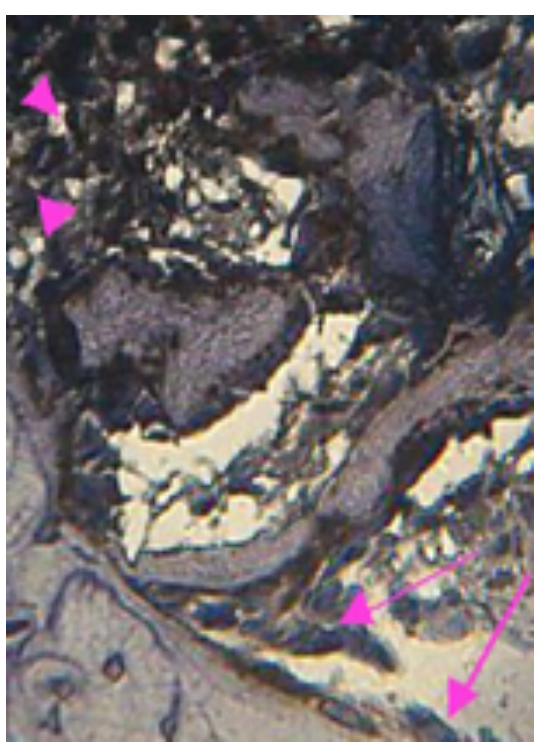

Figure(14) Osteoblast (arrow), osteocyte (arrow heads) expressed positive BMP2 in green tea gel group 10 days. DAB stain X40

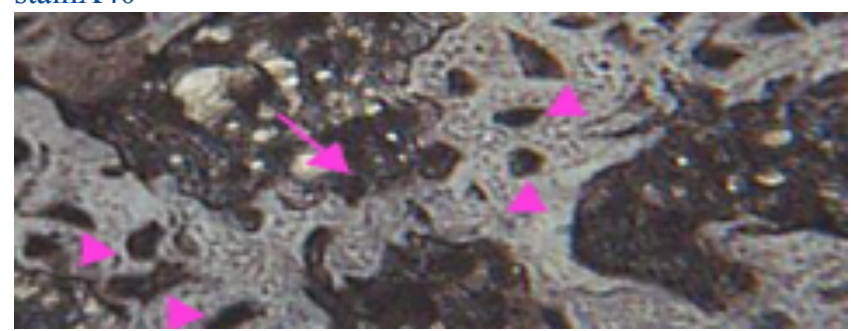

Control group shows an immunhistochemical view shows positive BMP2 expression by progenitor cell, inflammatory cell and endothelial cell in control group 3 days (Figure 9). Osteoprogenitor cell and osteoblast show positive BMP2 expression at 7 day (Figure 10). Osteoblast and reticular cell show positive BMP2 expression at 10 day (Figure 11).

\section{Experimental group of extracted green tea gel} illustrates an immunohistochemical view for positive BMP2 expressed by progenitor cell and endothelial cell in green tea gel group 3 days (Figure 12). Osteoblast and reticular cell show positive BMP2 expression at 7 day (Figure 13). Haversian canal (HC) content and active osteocyte in green tea gel 10 days show positive BMP2 expression (Figure 14).

\section{Statistical analysis of results}

Results for the mean of bone cells count at 7 period for all study groups illustrates a high significant difference value for green tea gel group in comparism to control group

Table 1: Descriptive statistics of the bone cells count (H\&E) and groups' difference in each duration

\begin{tabular}{|c|c|c|c|c|c|c|c|c|}
\hline \multirow{2}{*}{ Bone cells } & \multirow{2}{*}{ Duration } & \multirow{2}{*}{ Groups } & \multicolumn{4}{|c|}{ Descriptive Statistics } & \multicolumn{2}{|c|}{ Groups'difference } \\
\hline & & & Mean & S.D. & Min. & $\operatorname{Max}$. & $F$-test & p-value \\
\hline \multirow{4}{*}{ Osteoblast } & \multirow{2}{*}{7 days } & Control & 9.75 & 0.14 & 9.6 & 8.9 & \multirow{2}{*}{314.64} & \multirow{2}{*}{$\begin{array}{c}0.000 \\
\text { (HS) }\end{array}$} \\
\hline & & Green tea gel & 18.23 & 0.19 & 19 & 19.4 & & \\
\hline & \multirow{2}{*}{10 days } & Control & 7.83 & 0.12 & 7.7 & 7.9 & \multirow{2}{*}{25.26} & \multirow{2}{*}{$\begin{array}{c}0.000 \\
\text { (HS) }\end{array}$} \\
\hline & & Green tea gel & 7.85 & 0.08 & 7.8 & 7.9 & & \\
\hline \multirow{4}{*}{ Osteocyte } & \multirow{2}{*}{7 days } & Control & 13.80 & 0.10 & 12.7 & 12.9 & \multirow{2}{*}{310.89} & \multirow{2}{*}{$\begin{array}{c}0.000 \\
\text { (HS) }\end{array}$} \\
\hline & & Green tea gel & 15.25 & 0.18 & 16.1 & 16.4 & & \\
\hline & \multirow{2}{*}{10 days } & Control & 9.68 & 0.11 & 9.6 & 9.8 & \multirow{2}{*}{676.42} & \multirow{2}{*}{$\begin{array}{c}0.000 \\
\text { (HS) }\end{array}$} \\
\hline & & Green tea gel & 15.13 & 0.12 & 15 & 15.2 & & \\
\hline \multirow{4}{*}{ Osteoclast } & \multirow{2}{*}{7 days } & Control & 1.75 & 0.96 & 1 & 3 & \multirow{2}{*}{9.03} & \multirow{2}{*}{$\begin{array}{c}0.002 \\
\text { (HS) }\end{array}$} \\
\hline & & Green tea gel & 1.88 & 0.11 & 2.8 & 3 & & \\
\hline & \multirow{2}{*}{10 days } & Control & 0.80 & 0.46 & 0.4 & 2 & \multirow{2}{*}{8.45} & \multirow{2}{*}{$\begin{array}{c}0.003 \\
\text { (HS) }\end{array}$} \\
\hline & & Green tea gel & 0.20 & 0.09 & 0.2 & 0.4 & & \\
\hline
\end{tabular}

It has been shown that at 7 days duration the mean of the no. of osteoblast cells was significantly higher (18.23) $\mathrm{P}<0.001$ in the study group treated with green tea gel.

The mean of the no. of osteocyte cells was significantly higher $(15.25) \mathrm{P}<0.001$ in the study group treated with green tea gel at 7 days duration. The mean of no. of osteoclast cells was significantly higher $(1.88) \mathrm{P}<0.001$ in the study group treated with green tea gel at 7 days duration. 
Table 2: Descriptive statistics and duration difference of the positive stromal cells expressed by bone morphogenic protein 2

\begin{tabular}{|c|c|c|c|c|c|c|c|}
\hline \multirow{2}{*}{ Groups } & \multirow{2}{*}{ Duration } & \multicolumn{4}{|c|}{ Descriptive Statistics } & \multicolumn{2}{|c|}{ Duration difference } \\
\hline & & Mean & S.D. & Min. & $\operatorname{Max}$ & $F$-test & p-value \\
\hline \multirow{3}{*}{ Control } & 3 days & 33.53 & 2.47 & 30.2 & 35.5 & 252.24 & $\begin{array}{c}0.000 \\
\text { (HS) }\end{array}$ \\
\hline & 7 days & 30.23 & 0.19 & 30.1 & 30.5 & & \\
\hline & 10 days & 12.35 & 0.21 & 12.1 & 12.6 & & \\
\hline \multirow{3}{*}{ Green tea gel } & 3 days & 60.33 & 0.17 & 60.1 & 60.5 & 4914.83 & $\begin{array}{c}0.000 \\
(\mathrm{HS})\end{array}$ \\
\hline & 7 days & 49.55 & 0.41 & 49.1 & 50.1 & & \\
\hline & 10 days & 35.90 & 0.41 & 35.3 & 36.2 & & \\
\hline
\end{tabular}

Table 3: LSD test after ANOVA test

\begin{tabular}{|c|c|c|c|c|}
\hline Groups & \multicolumn{2}{|c|}{ Duration } & Mean Difference & p-value \\
\hline \multirow{3}{*}{ Control } & \multirow{2}{*}{3 days } & 7 days & 3.30 & 0.010 (HS) \\
\hline & & 10 days & 21.18 & 0.000 (HS) \\
\hline & 7 days & 10 days & 17.88 & 0.000 (HS) \\
\hline \multirow{5}{*}{ Green tea gel } & \multirow{2}{*}{3 days } & 7 days & 10.78 & 0.000 (HS) \\
\hline & & 10 days & 24.43 & 0.000 (HS) \\
\hline & \multirow{2}{*}{7 days } & 10 days & 13.65 & 0.000 (HS) \\
\hline & & 10 days & 48.98 & 0.000 (HS) \\
\hline & 7 days & 10 days & 12.15 & 0.000 (HS) \\
\hline
\end{tabular}

Table 2,3 show the statistics and duration difference of the positive stromal cells expressed bone morphogenic protein 2 and it represents a highly significant difference values for green tea gel group in comparism to control group.

\section{DISSCUSION}

Bone formation is a continuous process that begins during fetal development and persis throughout life as a remodeling process. In the event of injury, bones heal by generating new bone rather scar tissue (Carvalhol et al., 2012), to elucidate the extent to which skeletal regeneration affected by exogenous extracted green tea gel, we used detailed expression stages of bone apposition and ossification.

The present study shows an early ostoid deposition in extracted green tea gel group at 3 day period, as ostoid tissue formation, accompanied with significant immunopositive expression for bone morphgenic protein 2 in bone defect site. These results could be attributed to, that the traumatic site includes, stem cells differentiate into osteoblasts (Catharino et al., 2014) that enhanced by bone morphogenic protein 2 which has been implicated in angiogenesis and the proliferative osteoblast and active osteocyte were included in deposition of collagen fiber.

At $7 \& 10$ day periods, extracted green tea gel groups show trabeculae filled a proximately the whole defect in comparism to histologic views for control group. This result can be attributed that green tea gel directly promotes the differentiation of primary osteoblast, which is responsible for bone apposition and mineralization. The placebo-treated defects were not able to create a bony bridge across the gap. In contrast, green tea gel treatment caused significant filling with bone.

The present statistics analysis for the mean value of osteoblast, active osteocyte in green tea gel group, and stromal cells that expressed immunopositive reaction for bone morphogenic protein 2 were 
recorded to be a highly significant differences in comparison to control group.

By direct exposing the extracted green tea gel to bone defect, bone -forming cells from rats - called osteoblasts - to these green tea compounds, the research found that both the rate of bone growth and bone strengthening was significantly increased within a few days.

Some of this bone boosting affect comes down to the activity of a key enzyme that promotes bone growth. One particular green tea compound called Epi- gallo-catechin (EGC), led to an increase in this enzyme's activity by $79 \%$. It also increased levels of bone mineralization in these cells: a vital part of strengthening bones. Epi- gallo-catechin also suppressed the activity of cells called osteoclast cells that weaken and break down old bone, part of the natural process of bone remodelling. This study was conducted on rat bone cells, so further research is need to see if the same affect will hold true for human bone cells, this is acoincied with Chun et al.,2009 who was founded that catechin compound that present in green tea increase the harnessed of osteoporotic bone.

Our study shown that polyphenols which present in green tea (GTP) have positive effects on bone healing, this coincide with shen et al.,2008 who stated that the GTP prevented the aging-induced as well as aging plus estrogen deficiency-induced reduction in femoral bone mass.

\section{REFERENCE}

1. Ando K, Mori K, Rédini F, Heymann D. RANKL/RANK/ OPG: key therapeutic target in bone oncology.Curr Drug Discov Technol. 2008;5(3):263-8.

2. Carvalhol, L.R., Breyner, N., Hell, R., Valerio P. Healing Pattern in Calvaries Bone defects following bone regeneration in rats guided by chitosan scaffold and adipose tissue-derived mesenchymal stem cells. The open Tissue Engineering and Regenerative Medicine Journal. 2012; 5, 25-34.

3. Catharino P.C., Dominguez GC., Pinto Ddos S. Jr., Morea. Histomorphometric, and Radiographic Monitoring of Bone Healing Aroundlnoffice-Sterilized Orthodontic Miniimplants With or Without Immediate Load: Study in Rabbit Tibiae. IntJ. Oral Maxillofac Implants. 2014;Mar-Apr 29(2), 321-30.
4. Choi EM, Hwang JK. Effects of (+)-catechin on the function of osteoblastic cells. Biol Pharm Bull.2003;26(4):523-6.

5. Chun Hay Ko, Kit Man Lau, Wing Yee Choy, Ping Chung Leung. Effects of Tea Catechins, Epigallocatechin, Gallocatechin, and Gallocatechin Gallate, on Bone Metabolism. Journal of Agriculture and Food Chemistry. 2009; 57, 7293-7297.

6. Chwan-Li Shen, James K. Yeh, Jay J. Cao, Ming-Chien Chyu, and Jia-Sheng Wang. Green Tea and Bone Health: Evidence from Laboratory Studies Pharmacol Res. 2011Aug; 64(2): 155-161.

7. Hillmann, G., Gebert, A., Geurtsen W. Matrix expression and proliferation of primary gingival fibroblasts in three dimensional cell culture mode, Jounal of Cell Science. 1999; 117. 2823-2832.

8. Matsuo K, Irie N. Osteoclast-osteoblast communication. Arch BiochemBiophys. 2008;473(2):201-9

9. Nijweide PJ, Burger EH, Feyen JH. Cells of bone: proliferation, differentiation, and hormonal regulation. Physiol Rev. 1986;66(4):855-86. Review].

10. Shen CL, Wang P, Guerrieri J, Yeh J, Wang JS. Protective effect of green tea polyphenols on bone loss in middle-aged female rats. Osteoporosis Int. 2008;19(7):979-90.

11. Shen CL, Wang P, Guerrieri J, Yeh J, Wang JS. Protective effect of green tea polyphenols on bone loss in middle-aged female rats. Osteoporosis Int. 2008;19(7):979-90.

12. Shen CL, Yeh JK, Cao JJ, Tatum OL, Dagda RY, Wang J-S. Green tea polyphenols mitigate bone loss of female rats in a chronic inflammation-induced bone loss model. J Nutr Biochem. 2009;21:968-74. 2010.

13. Shen CL, Yeh JK, Samathanam C, Cao JJ, Stoecker BJ, Dagda RY, Chyu MC, Dunn DM, Wang JS. Green tea polyphenols attenuate deterioration of bone microarchitecture in female rats with systemic chronic inflammation. Osteoporosis Int. 2010 Mar 20; [Epub ahead of print]. PMID: 20306019.

14. Shen CL, Yeh JK, Stoecker BJ, Chyu MC, Wang JS. Green tea polyphenols mitigate deterioration of bone microarchiteture inmiddle-agedfemalerats. Bone. 2009;44(4):684-90.

15. Singer F.R, and Eyre D.F. 2011. Using biochemical markers of bone turnover in clinical practice. Cleveland Clin J Med. 75 (10): 73-750.

16. Wang JS, Luo H, Wang P, Tang L, Yu J, Huang T, et al. Validation of green tea polyphenol biomarkers in a phase II human intervention trial. Food Chem Toxicol. 2008;46(1):232-40.

17. Yang CS, Landau JM. Effects of tea consumption on nutrition and health. J Nutr. 2000;130:2409-12. 